\title{
Influence of End-Plates on Biomechanical Response of the Human Lumbosacral Segment
}

\author{
Vincenzo Moramarco', Claudia Macchia1, \\ Carmine Pappalettere ${ }^{1}$ and Amaya Pérez del Palomar ${ }^{2}$ \\ ${ }_{1}^{1}$ Politecnico di Bari, Dipartimento di Ingegneria Meccanica e Gestionale \\ ${ }^{2}$ Universidad de Zaragoza, Departamento de Ingenieria Mecanica \\ ${ }^{1}$ Italy \\ ${ }^{2}$ Spain
}

\section{Introduction}

Diseases of lumbar spine and associated diseases of the intervertebral disc are a major focus of contemporary spinal care. Low back pain, in fact, is becoming in the recent years one of the most diffuse chronic pathologies and represents one of the highest direct and indirect costs for national welfare. It can affect for years the patient with obvious disabling consequences and many times without a complete explanation of the causes (Devor \& Tal, 2009).

Some clinical studies (Latorraca \& Forni Niccolai Gamba, 2004) showed that the greatest proportion (about $90 \%$ ) of spinal diseases, like lumbar hernias, is located in the lumbar spine segment. Recent investigations based on clinical-radiological observations pointed out those rachidian affections such as lumbar and sciatic pains that in the worst cases last for years with very invalidating effects on the patient mainly depending on disk-vertebral insufficiency caused by degenerative phenomena. At the same time, in absence of pathological disease, daily activities, lifting stationary work postures, heavy physical work and vibrations are factors that contribute to low back disorders (Natarajan et al., 2004).

Usually, orthopaedic therapy is essentially based on the experience of the surgeon who predicts the best solution for each patient. Using mathematical models and computer simulations could potentially be an important tool to support clinical decisions in order to predict the appearance and evolution of spine pathologies, for preoperative planning and implant design.

The present work is focused on the analysis of the lumbar spine with the aim of studying the influence and the roles that the different components of the spine play on its biomechanical response.

In particular the presence of the cartilagineous endplates separating the soft tissues of the intervertebral disc from the strong bone of the vertebrae will be studied.

The endplates, in fact, are demonstrated to perform a double function in the global response of the spine respectively mechanically "protecting" the discs from a direct contact with the vertebrae avoiding the disc to bulge axially under compression and, at the same time, acting as the favourite nutrients transport route for the same discs. The endplates also absorb the 
considerable hydrostatic pressure that results from mechanical loading of the spine (Broberg, 1983).

Although the cartilaginous end-plates (CEP) play a great role in the biomechanics of the intervertebral discs (Adams \& Roughley, 2006), most authors (Eberlein et al., 2004; Rohlmann et al., 2006; Moramarco et al., 2010) did not consider the presence of the CEP in their models or simulated it using the same mechanical properties of the annulus fibrosus (Zander et al., 2009).

In order to understand the influence of the CEP in the modelling of the lumbar spine segment two accurate computational models, with and without CEP, of the whole lumbosacral spinal unit (L1-S1) of the human rachis, based on CT-scan imaging and experimental data, were built and their mechanical response under static loading was compared.

\section{Model}

The lumbar spine is the most caudal part of the articulated vertebral column and it normally supports the highest mechanical loads. In a person who does not carry extra weight, the lumbar structure bears at least $55 \%$ of the total body mass (Noailly, 2009). In particular the lumbar spine is composed of five vertebrae and the sacrum, a large, triangular bone, that consists of five vertebrae fused together. Between each vertebra there is a disc that serves to cushion the vertebrae and connect them together in a flexible way. The disc and the surface of the vertebrae are separated by a cartilaginous endplate which is the interface that avoids the direct contact between the two components above mentioned.

An accurate FE computational model of the complete L1-S1 segment of the human rachis of a real patient, based on CT-scan imaging and experimental data, has been built in order to simulate the non-linear behaviour of the rachis measured in vitro. In particular with the aim of studying the mechanical role of the cartilaginous endplates, two models, differing exclusively in the presence of the endplates, will be presented.

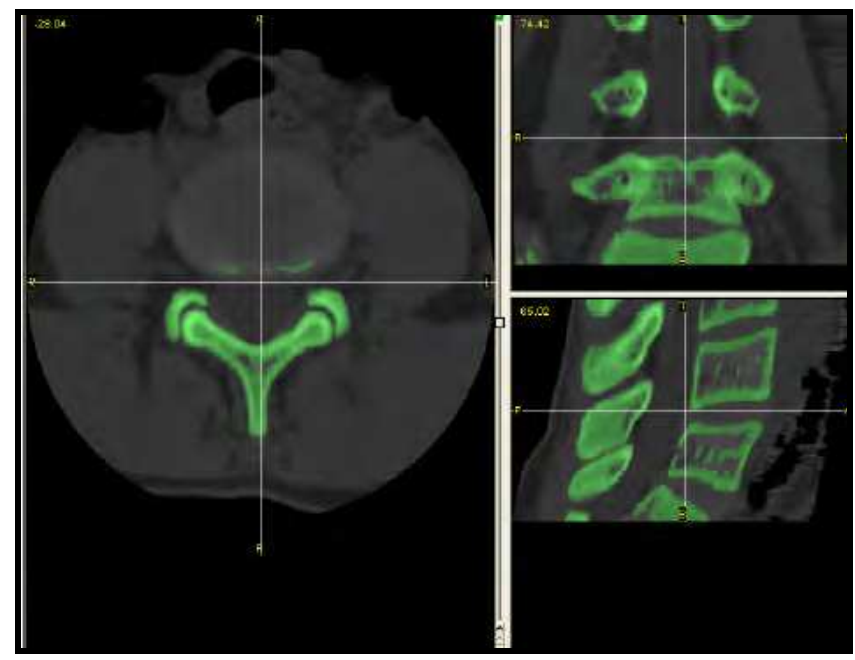

Fig. 1. CT data scan of the human lumbosacral region. 


\subsection{Vertebrae geometry definition}

To reconstruct the FE model of the healthy lumbar segment, CT scan data of a subject with no current spinal pathology consisting of 101 slides each of $0.90 \mathrm{~mm}$ were used (Fig. 1).

The reconstruction of three-dimensional models of the vertebrae was performed using the software Mimics ${ }^{\circledR} 10.0$ by Materialise Inc, in particular the domain boundary of each vertebra was created individually, using the built-in module MedCAD ${ }^{\circledR}$ available in the software application.

For this, it is essential to define the edges of the vertebra separating them from the bottom of the initial image. This is done initially relying on the different gray value of the CT image, a different gray level indicates a different density of the object in the image, so it is possible to define a threshold level that separates the parts of interest from the background. All pixels with a grey level higher than the threshold are considered part of the vertebra. In this case the upper threshold level was set to 1200 of the Hounsfield scale while the lower level to 200 (Fig. 2).
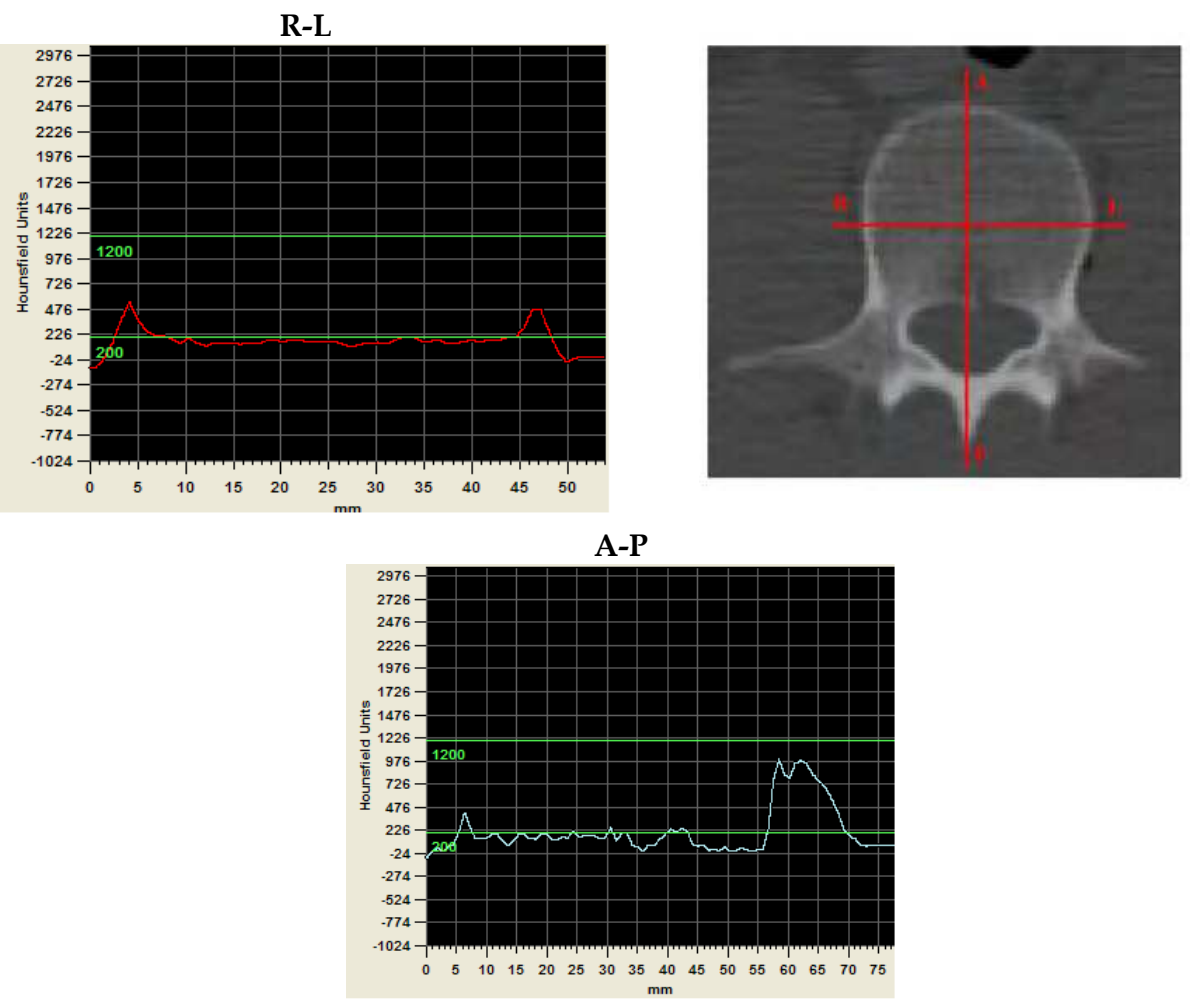

Fig. 2. An example of the anterior-posterior (A-P) and right-left (R-L) Hounsfield scale profiles. 
The pixels selected in all the slides and in all three planes (sagittal, transverse end axial) of the CT file are joined together using the so-called "mask".

An example of "mask" in which the threshold was set in order to select the areas of the bone is shown in green in Fig.1. In the same figure it is evident that selecting the single vertebra is not possible and that there are cavities in the mask.

For this reason after creating the mask on the different gray levels the masks of the single vertebrae must be created and adjusted in order to obtain a refined mask which allows the software to calculate the three-dimensional model of the single vertebra (Fig 3).

In order to preserve the original geometry as well as possible no smoothing operations were carried out on the surfaces.

The 3D models thus obtained can be converted into formats readable from other softwares, such as those for the finite element analysis (FE).

In our case the models of individual vertebrae of the lumbar-sacral segment L1-S1 were exported in the *.inp format readable by the commercial FE software ABAQUS ${ }^{\circledR}$ which will be used later to carry out the numerical simulations.

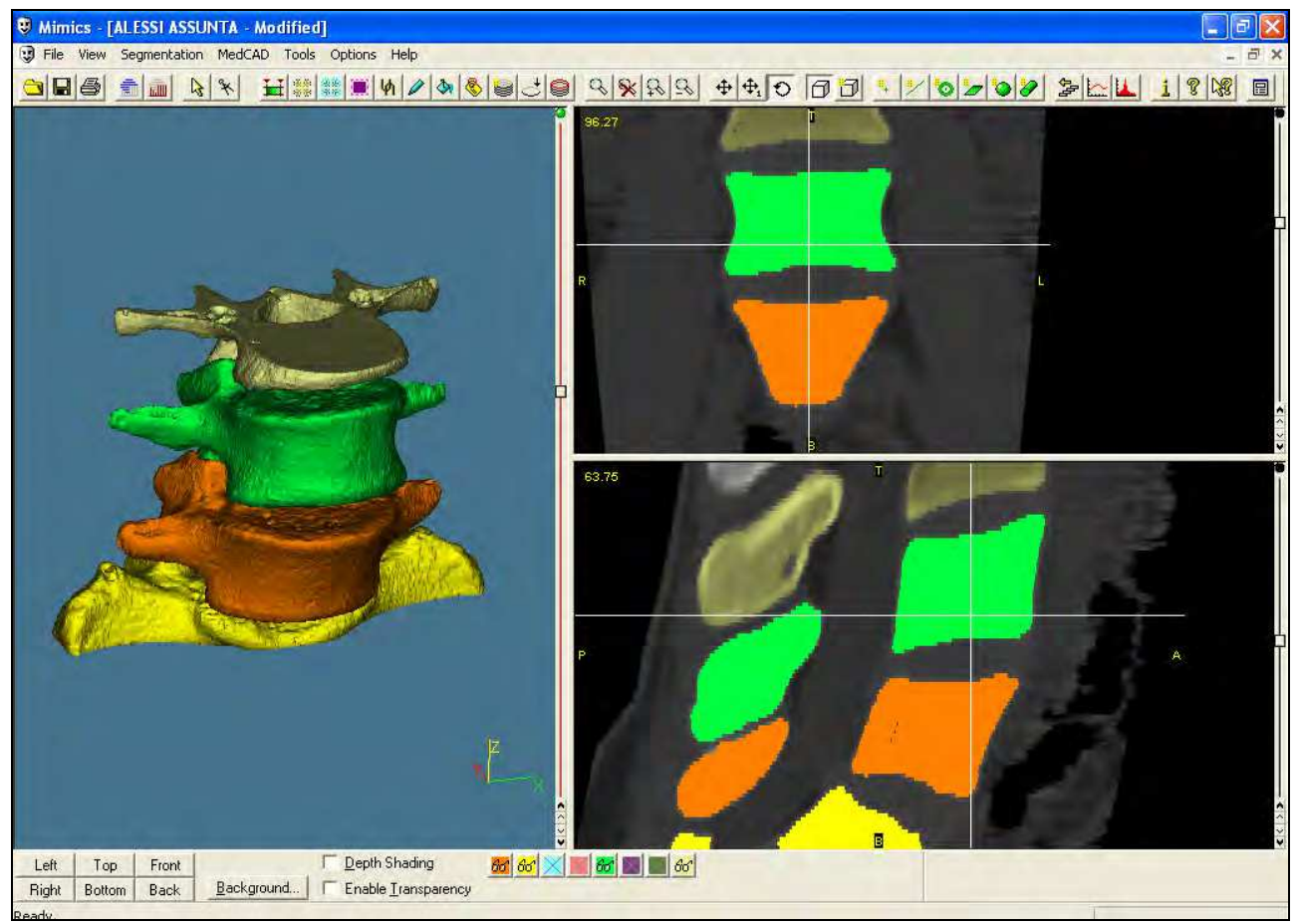

Fig. 3. Domain boundary creation with Mimics ${ }^{\circledR}$.

Then, the vertebrae were discretized using surface triangular 3-nodes elements and reassembled preserving the original positions. The single vertebrae were imported in ABAQUS where they were assembled to create the complete model of the lumbar spine having the same geometry of the real one obtained with CT scan (Fig. 4). 


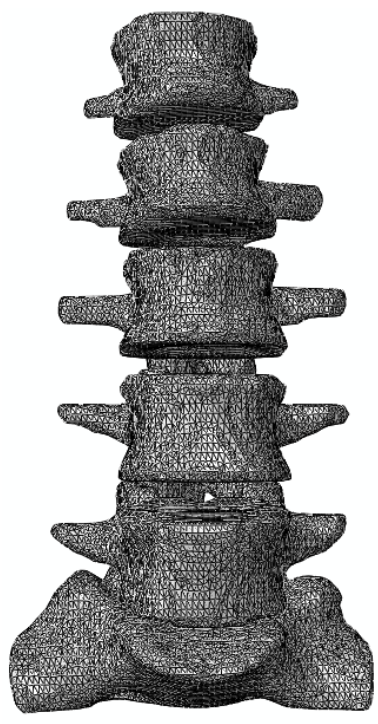

(a)

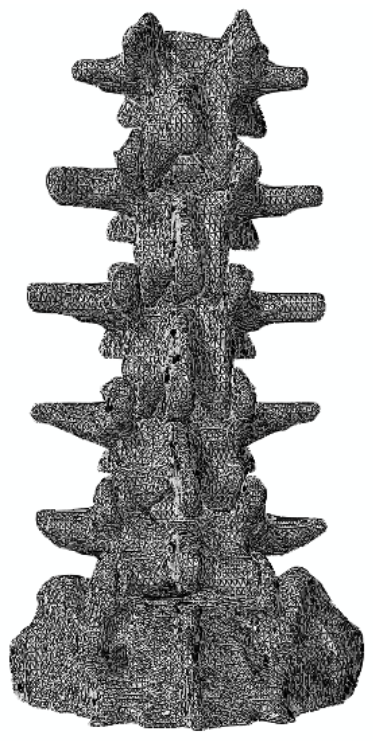

(b)

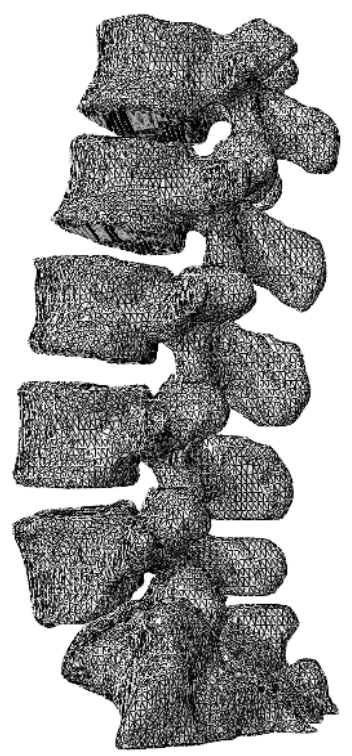

(c)

Fig. 4. Front (a), back (b) and lateral (c) view of the discretized lumbosacral segment of the human rachis.

\subsection{Intervertebral disc (IVD) geometry definition}

The intervertebral discs were modelled with deformable elements. The soft tissues, unlike the tissues characterized by high density as the bone, are not directly visible in a normal CT scan. For this reason the creation of the disc has been based not only on the CT data but also on anatomical studies present in literature.
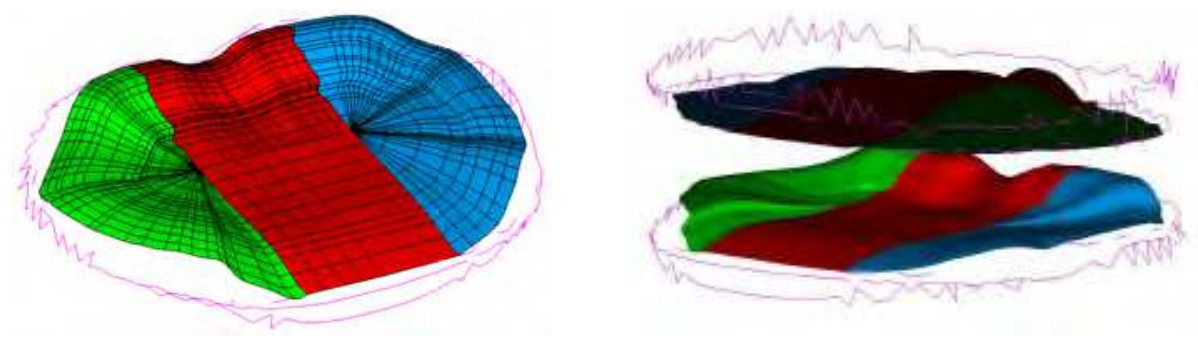

Fig. 5. Superior and inferior surfaces of the disc obtained with I-DEAS

The upper and the lower surfaces of each disc were defined using the surface of the vertebrae above and below respectively. The software I-Deas 9 (Altair Computing Inc.) (Structural Dynamics Research Corporation, 1993) was used to generate these surfaces (Fig 5.).

Then, using Cubit 10.1 (Leland, 2001), the volume domain was generated and the annulus fibrosus and the nucleus pulposus were drawn so that volumetric ratio was 3:7 like reported in Goto et al. (2002). The domain was discretized with 8-node hexahedral elements. Figure 6 
shows the intervertebral disc as it has been obtained in CUBIT. Two zones, the nucleus pulposus and the annulus fibrosus can be distinguished.

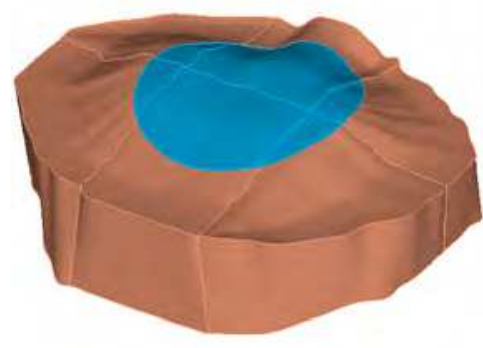

(a)

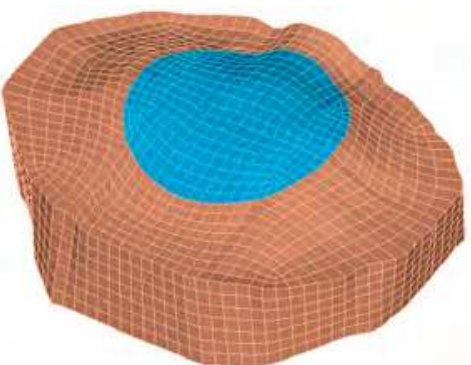

(b)

Fig. 6. Intervertebral disc obtained in CUBIT 10.1: before (a) and after (b) meshing

Finally all disc meshes were adjusted to the related vertebrae surfaces in order to obtain a perfect continuity and to remove interferences between the bodies (Fig. 7).

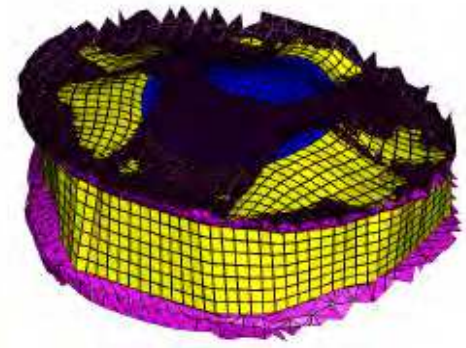

(a)

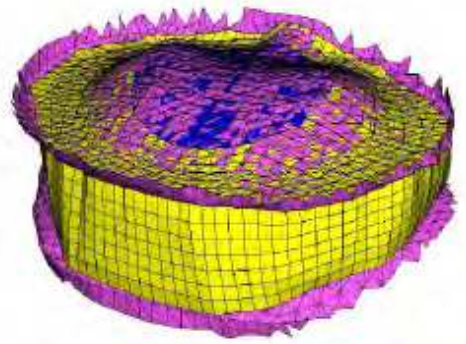

(b)

Fig. 7. L4-L5 intervertebral disc volume definition: bodies interferences removal

\subsection{Cartilaginous endplates (CEP)}

The cartilaginous endplate, being considered as a part of the soft intervertebral disc, has been constructed using the surfaces of each disc. In this way the geometry and the condition of non-interference with the surfaces of the vertebrae were respected.

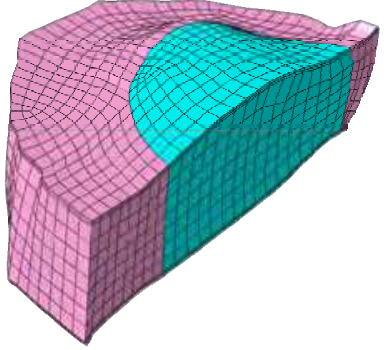

(a)

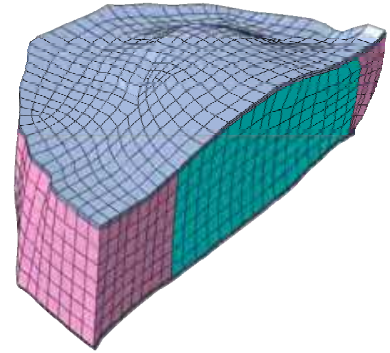

(b)

Fig. 8. Intervertebral disc without (a) and with (b) endplate 
In particular each endplate has been carried out with two layers, each with $0.5 \mathrm{~mm}$ thick and characterized as a linear elastic material.

The elastic response of the cartilaginous endplates is purely isotropic. Only tensile stress is sustained by the one-dimensional collagen fibres (Eberlein et al., 2001).

\subsection{The whole model of the lumbosacral segment L1-S1}

The whole model was assembled using ABAQUS CAE 6.8. The relative position of all parts, the geometry and the natural curvature of the spine were preserved. The ligaments, anterior longitudinal (ALL), posterior longitudinal (PLL), intertransverse (ITL), flavum (LF), capsular (JC), interspinous (ISL) and supraspinous (SSL) were added.

\begin{tabular}{|c|c|c|c|c|c|}
\hline Ligament & $E_{1}[\mathrm{MPa}]$ & $E_{2}[\mathrm{MPa}]$ & $\varepsilon_{12}$ & Elements & Area $\left[\mathrm{mm}^{2}\right]$ \\
\hline ALL & 7.8 & 20.0 & 0.12 & 5 & 32.4 \\
\hline PLL & 1.0 & 2.0 & 0.11 & 5 & 5.2 \\
\hline LF & 1.5 & 1.9 & 0.062 & 3 & 84.2 \\
\hline ITL & 10.0 & 59.0 & 0.18 & 4 & 1.8 \\
\hline SSL & 3.0 & 5.0 & 0.20 & 3 & 25.2 \\
\hline Ligament & Spine Level & Area $\left[\mathrm{mm}^{2}\right]$ & $\begin{array}{l}\text { Poisson's } \\
\text { Ratio v }\end{array}$ & Elements & $\begin{array}{l}\text { Stiffness } k \\
{[\mathrm{~N} / \mathrm{mm}]}\end{array}$ \\
\hline \multirow[t]{5}{*}{ JC } & L1-L2 & 43.8 & 0.4 & 6 & 42.5 \\
\hline & L2-L3 & & & & 33.9 \\
\hline & L3-L4 & & & & 32.3 \\
\hline & L4-L5 & & & & 30.6 \\
\hline & L5-S1 & & & & 29.9 \\
\hline \multirow[t]{5}{*}{ ISL } & L1-L2 & 35.1 & 0.4 & 6 & 10.0 \\
\hline & L2-L3 & & & & 9.6 \\
\hline & L3-L4 & & & & 18.1 \\
\hline & L4-L5 & & & & 8.7 \\
\hline & L5-S1 & & & & 16.3 \\
\hline
\end{tabular}

Table 1. Lumbar ligaments properties (Pintar et al., 1992; Chazal et al., 1985; Goel et al.,1995; Goto et al., 2003).

Since they are able to response only at traction loads, they were modelled as tension only nonlinear truss elements with the features described in the table below.

The finite element model was formed of six vertebrae, from the L1 to the S1, and five intervertebral discs interposed between them. The ligaments were placed in the model so that the natural configuration was respected.

The model contains 128793 elements, in particular 46887 hexaedrical 8-nodes elements (C3D8) for the nucleus, the annulus and the endplates, 73016 rigid elements (R3D3) to simulate bone behaviour and 180 truss (T3D2) elements for the ligaments.

Contact constrain was activated between the facets of the posterior processes using $30 \mathrm{GAP}$ elements. Gap elements allow the nodes to be in contact (gap closed) or separated (gap 
open) with respect to particular directions and separation conditions. The whole model with all its component is shown in Fig. 9.

In all conducted FE simulations bones were modelled as rigid bodies; in fact, they are much stiffer than the soft tissues present in the model and their deformation can be consider negligible in comparison with those undergone by the latter.

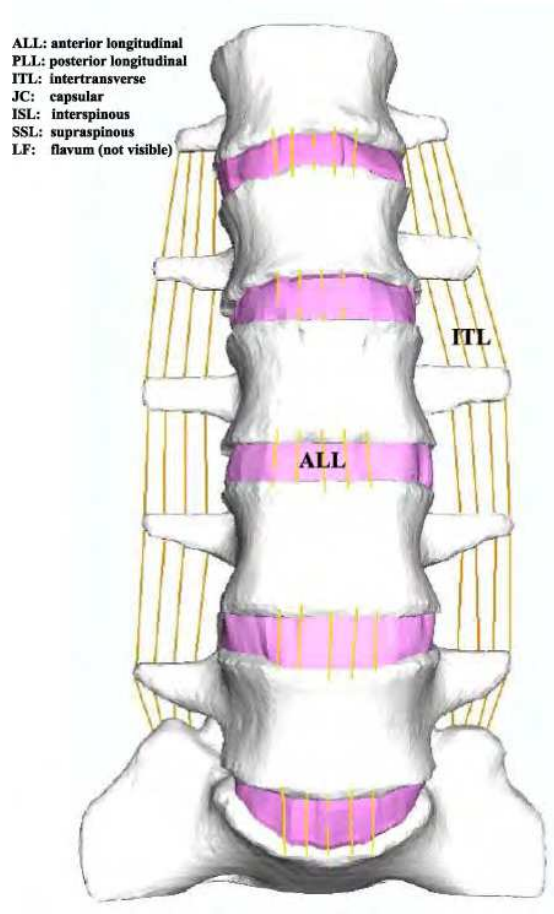

(a)

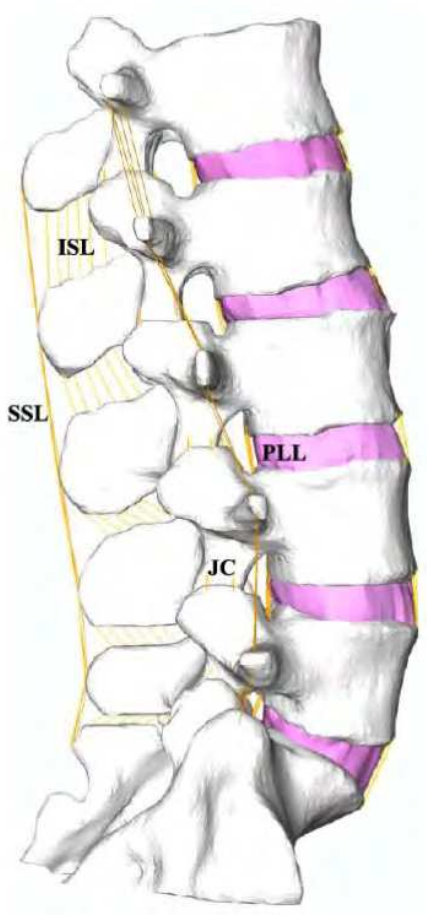

(b)

Fig. 9. Complete finite element model of the spinal segment L1-S1: (a) front view and (b) lateral view.

The constitutive equation for modelling the mechanical behaviour of the intervertebral disc was implemented in a user defined UMAT subroutine for ABAQUS. A hyperelastic fibrereinforced model with two families of fibres (Holzapfel, 2000) was used to simulate the anisotropic behaviour of this soft tissue (Eberlein et al.,2001; Perez del Palomar et al., 2008). The strain energy function used for this hyperelastic material is given by

$$
\begin{aligned}
& \Psi=\mathrm{C}_{10}\left(\overline{\mathrm{I}}_{1}-3\right)+\mathrm{C}_{01}\left(\overline{\mathrm{I}}_{2}-3\right)+\mathrm{C}_{20}\left(\overline{\mathrm{I}}_{1}-3\right)^{2}+\mathrm{C}_{02}\left(\overline{\mathrm{I}}_{2}-3\right)^{2} \\
& +\mathrm{C}_{11}\left(\overline{\mathrm{I}}_{1}-3\right)\left(\overline{\mathrm{I}}_{2}-3\right)+\frac{\mathrm{K}_{1}}{2 \mathrm{~K}_{2}}\left\{\exp \left[\mathrm{K}_{2}\left(\overline{\mathrm{I}}_{4}-1\right)^{2}\right]-1\right\} \\
& +\frac{\mathrm{K}_{1}}{2 \mathrm{~K}_{2}}\left\{\exp \left[\mathrm{K}_{2}\left(\overline{\mathrm{I}}_{6}-1\right)^{2}\right]-1\right\}+\frac{1}{\mathrm{D}}(\mathrm{J}-1)^{2}
\end{aligned}
$$


where $\mathrm{Cij}$ are material constants related to the ground substance, $K_{1}$ and $K_{2}$ are the parameters which identify the exponential behaviour due to the presence of collagen fibres of both families (note that here to simplify the model, the same response was assumed for both families ) and D identifies the tissue incompressibility modulus. The invariants are defined as:

$$
\begin{gathered}
\overline{I_{1}}=\operatorname{tr} \bar{C} \quad \overline{I=\frac{1}{2}}\left[(\operatorname{tr} \bar{C})^{2}-\operatorname{tr}(\bar{C})^{2}\right] \\
\overline{I_{4}}=a^{D} \cdot \overline{C a^{D}} \quad \bar{I}=b^{D} \cdot \bar{C} b^{D}
\end{gathered}
$$

where $a^{D}$ is the unitary vector defining the orientation of the first family of fibers, $b^{D}$ the direction of the second family both in the reference configuration and $\bar{C}$ is the modified right Green strain tensor:

$$
\bar{C}=\bar{F}^{T} \bar{F} \quad \text { with } \quad \bar{F}=J^{\frac{1}{3}} F
$$

being $\mathrm{F}$ the deformation gradient and $\mathrm{J}=\operatorname{det}(\mathrm{F})$.

Each family of fibres was placed circumferentially around the nucleus with an orientation of $\pm 30^{\circ}$ with respect to the disc plain (Goel et al.,1995). The values of the elastic constants were determined using the stress-strain response under a traction axial load for a specimen with two families of fibres, placed at $\pm 30^{\circ}$. The theoretical model behaviour was fitted to experimental data presented by Ebara et al. (1996) using MatLab v.7.1. It can be observed (Fig. 10) how the resultant curve can be considered a good average fit of experimental data of the whole annulus.. Moreover the magnitude of the found values for the material constants was in the range of the available data in the literature (Ebara et al., 1996; Eberlein et al., 2001; Zander et al., 2009).

To define the nucleus pulposus it was considered that the behaviour of this part was isotropic and almost incompressible, so it was modelled as a hyperelastic Neo- Hookean material with material constants $C_{10}=0.16 \mathrm{MPa}$ and $\mathrm{D}=0.024 \mathrm{MPa}$ (Perez del Palomar et al., 2008). Contact

\begin{tabular}{|c|c|c|c|}
\hline Component & Notes & Element type & $\begin{array}{c}\text { Material } \\
\text { constants }\end{array}$ \\
\hline End-plates & Linear elastic & C3D8 & $\mathrm{E}=20 \mathrm{MPa}, \mathrm{v}=0.4$ \\
\hline Bone & Rigid body & R3D3 & \\
\hline Nucleus Pulposus & $\begin{array}{l}\text { Hyperelastic } \\
\text { neo-Hookean }\end{array}$ & C3D8 & $\begin{array}{l}C_{1}=0.16 \mathrm{MPa} \\
D=0.024 \mathrm{MPa}^{-1}\end{array}$ \\
\hline Annulus Fibrosus & $\begin{array}{l}\text { Hyperelastic fibred- } \\
\text { reinforced material }\end{array}$ & C3D8 & $\begin{array}{l}C_{10}=0.1 \mathrm{MPa} \\
C_{20}=2.5 \mathrm{MPa} \\
K_{1}=1.8 \mathrm{MPa} \\
K_{2}=11 \\
D=0.306 \mathrm{MPa}^{-1} \\
a= \pm 30^{\circ}\end{array}$ \\
\hline $\begin{array}{l}\text { Posterior processes } \\
\text { contact }\end{array}$ & & GAP & \\
\hline
\end{tabular}
constrain was activated between the facets of the posterior processes using GAP elements. Table2 sums up all mechanical and element type properties of the model.

Table 2. Material properties in the finite element model (Moramarco et al., 2010) 


\section{Numerical analysis}

In order to study the influence of the cartilaginous endplates on the biomechanical response of the lumbo-sacral segment, two distinct models reproducing the lumbar rachis were created. The behaviour of a complete model provided of six vertebrae, five discs and two endplates for each disc was compared with a model identical to the previous but without endplates.

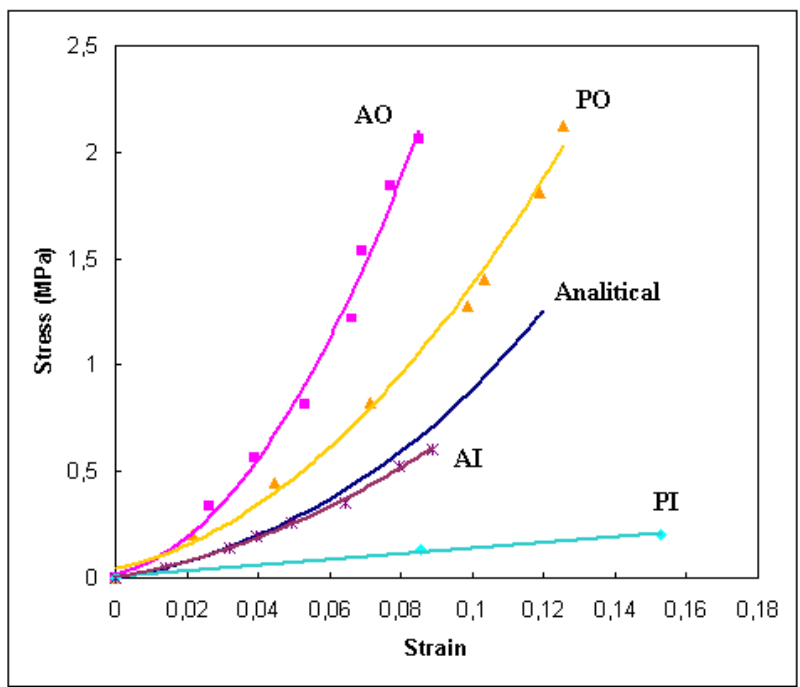

Fig. 10. Comparison between experimental data, measured by Ebara et al. (1996), and the analytical curve using our constants $(\mathrm{AO}=$ anterior outer annulus ; $\mathrm{PO}=$ posterior outer annulus; $\mathrm{AI}=$ anterior inner annulus; $\mathrm{PI}=$ posterior inner annulus)

The exact mechanical role of the endplates has not been described satisfactorily in literature. In this section we will show that the presence of the endplate acting as an interface between the vertebral bodies and the discs (Kramer 2009) is important to reduce the stresses in the disc when the spine is loaded.

\subsection{Boundary conditions}

To demonstrate the goodness of this model the in vitro tests performed by Panjabi et al. (1994) were reproduced in silico under similar conditions. The proposed test includes the study of a sample of whole fresh-frozen human cadaveric lumbosacral-spine specimens in which muscles and soft tissues, except ligaments, were removed.

The lower lumbar vertebra of each specimens obtained was fixed to the test table while the loads were applied to the most cephalic (the first or second lumbar) vertebra. The vertebrae were unconstrained, to allow natural physiological movements of the spine to occur in response to the applied load (Panjabi et al., 1994).

In the experimental test the specimens were loaded by pure flexion and extension moments both of $10 \mathrm{Nm}$, applied incrementally to the most cephalic vertebra by equal and opposing forces generated by pneumatic actuators. Throughout the testing, a compressive pre-load of $100 \mathrm{~N}$ was applied along the longitudinal axis of the specimen (Panjabi et al., 1994). 
The numerical model implemented was tested under the same load and boundary conditions proposed in the experimental experience in order to validate the model and numerically prove the nonlinear behaviour of the model in the entire flexion-extension range of the movement (Fig. 11).

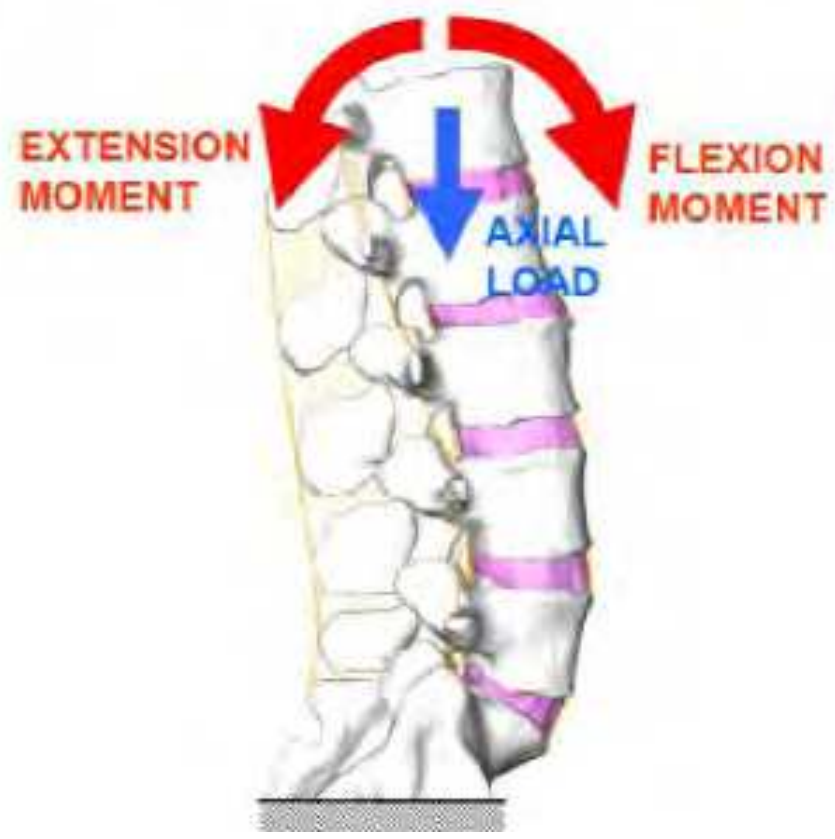

Fig. 11. Schematic representation of load and boundary conditions applied to the numerical model.

The tests were performed with two models of the lumbar spine differing in the presence of the cartilaginous endplates using Abaqus 6.8.

In agreement with the data reported in literature the relative rotation angle between each pair of adjacent vertebrae was measured and plotted in function of the applied moment.

\subsection{Cinematic response comparison}

Figure 12 shows the comparison between the experimental results and the values obtained in the numerical simulations relative to the models with and without endplates.

Firstly, analyzing the numerical results, it is possible to state that the model presents a good agreement with the experimental data with the numerical curve falling within the experimental standard deviation interval.

The results show that the presence of the CEP permits to obtain a grater no-linearity of the spine response but a small decrease of the predicted ROM in flexion.

In particular in extension the curves representing the rotation angles for the numerical model displays a good concordance with the experimental ones especially for L1-L2, L2-L3 and L5-S1 segments. The curves for the model with endplates follow with a very small error the trend of the experimental results. 

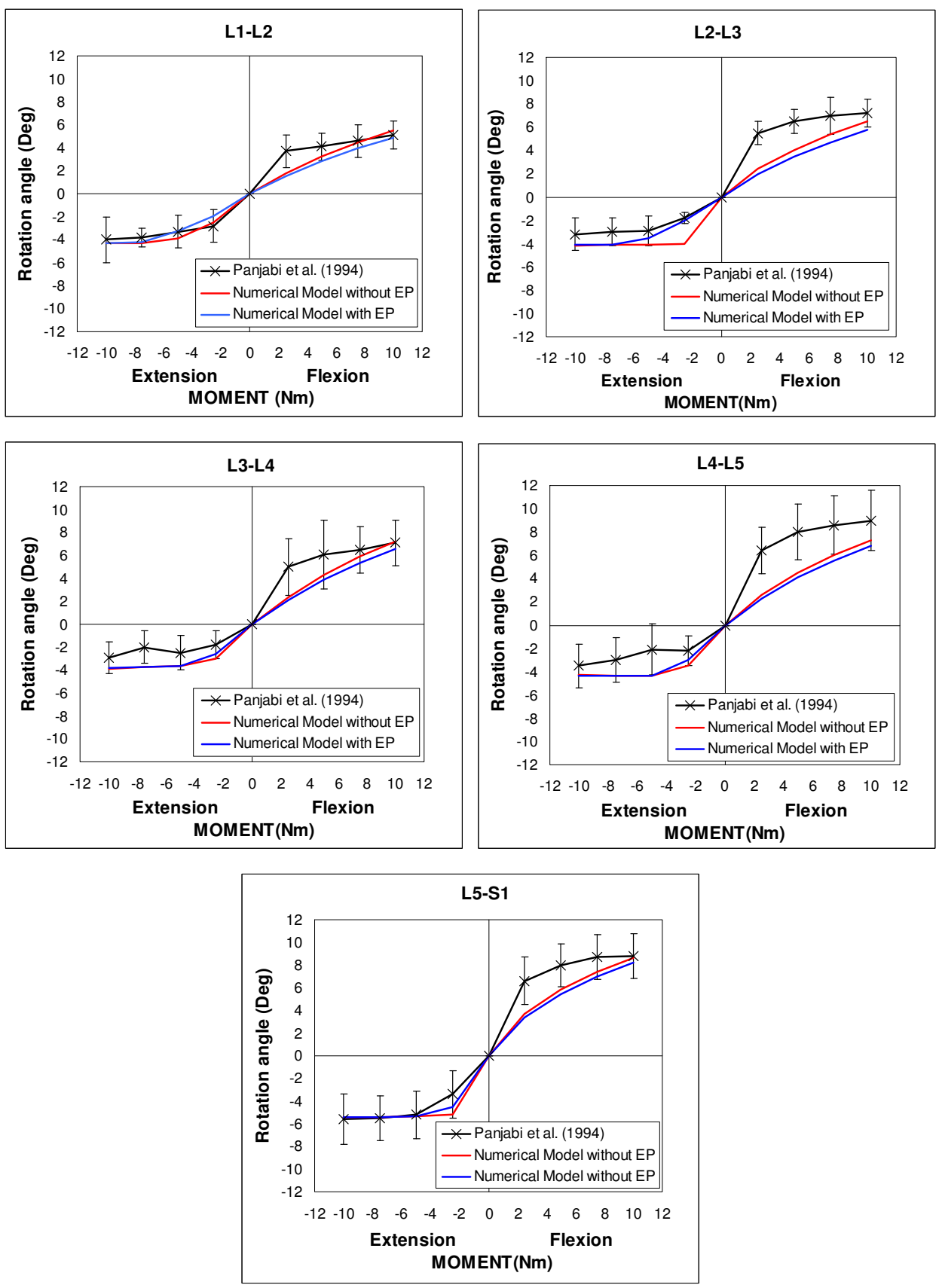

Fig. 12. Comparison between the relative rotation angle under flexion-extension moment predicted by the FE model and that measured by Panjabi et al. (1994). 
In particular for the L2-L3 segment is evident a remarkable difference between the two numerical models in analysis showing a great improvement in the results obtained. The maximum deviation from the experimental results obtained in the model with endplates in this segment is in the range of $0.9^{\circ}$ while the model without endplates shows a maximum error of $2^{\circ}$. In flexion the two numerical models do not show a noticeable difference. The curves are similar with slightly higher rotation angles for the model without endplates. The maximum difference encountered between the numerical models is obtained at L2-L3 level with a deviation of $0.7^{\circ}$.

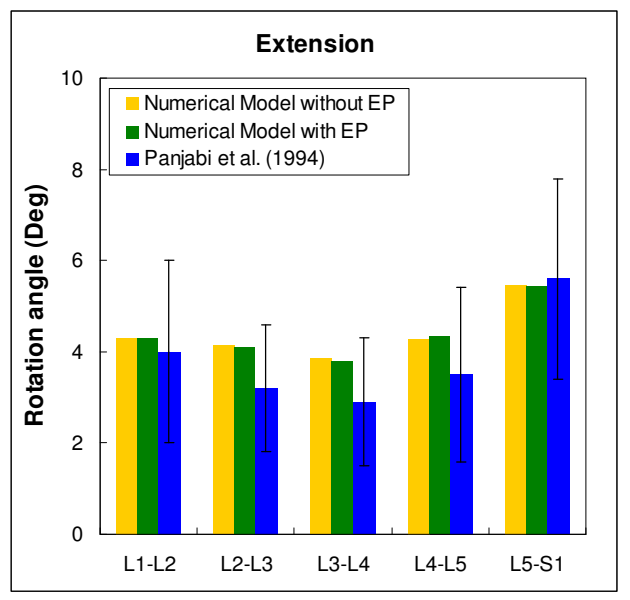

(a)

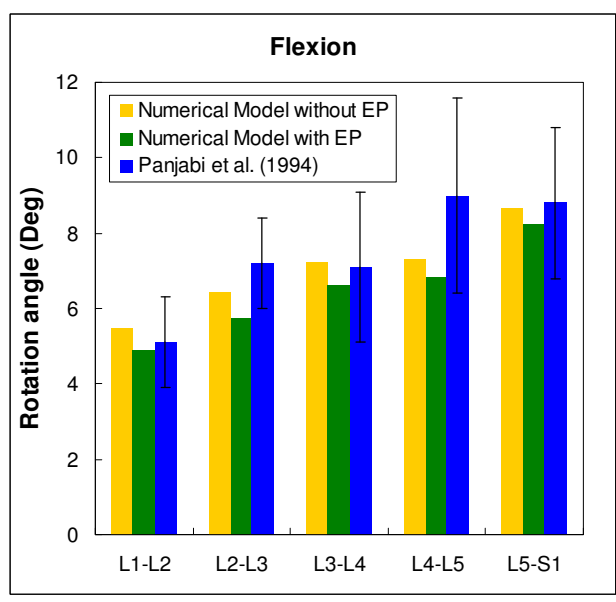

(b)

Fig. 13. Maximum relative rotation angle measured with the numerical model with endplates and without endplates compared with the experimental results (M.M. Panjabi 1994) for an extension (a) and a flexion (b) test.

In Fig.13 the maximum (flexion) and the minimum (extension) relative rotation angles obtained in the two analysis are shown and compared with the experimental results. The correspondence with the experimental values is almost perfect in extension for the L5-S1 segment in which we obtain for the complete model (with endplates) a maximum rotation of $5.4^{\circ}$ against the $5.6^{\circ}$ calculated in the experimental analysis. The agreement is good also at L1-L2 level in which we obtain a value of $4.3^{\circ}$ against the experimental value of $4^{\circ}$. In flexion the segment L1-L2 shows the best results with an error of $0.2^{\circ}$ between the numerical and experimental. As stated before the model without endplates shows higher rotation values in flexion. According to experimental data, there is clearly increasing motion moving inferiorly from the level between the first and second lumbar vertebrae to that between the fifth lumbar and first sacral vertebra. The ROM for the maximum flexion moment of the segments L5-S1, in fact, results substantially higher than for the other segments.

All the considerations made so far are confirmed in Fig. 14 in which the relative rotations between the five vertebrae are represented. In fact, comparing the ROM for a $10 \mathrm{Nm}$ flexoextension moment, it is possible to remark that the three models have the same distribution of the ROM between all the different segments with the curves of the numerical model perfectly falling within the standard deviation interval. 


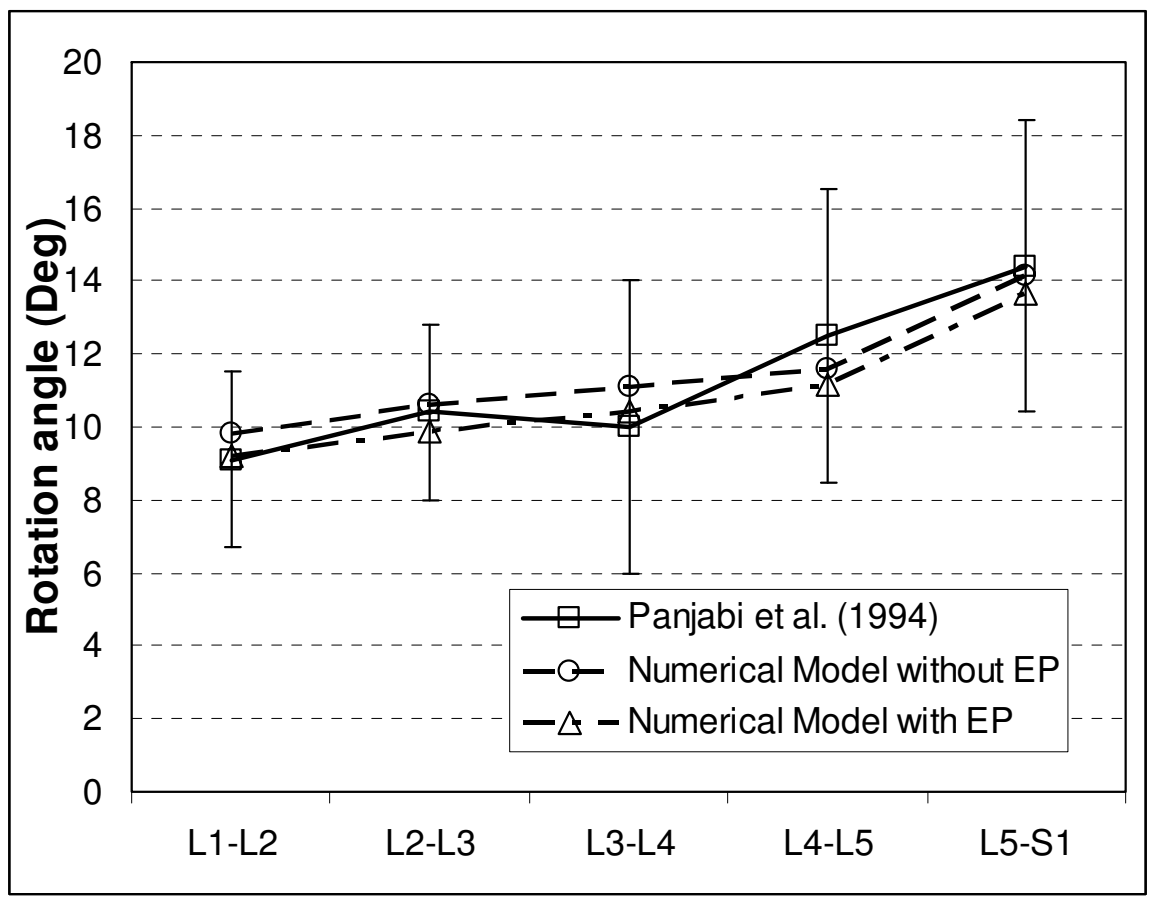

Fig. 14. Comparison between the relative rotation angles under a $10 \mathrm{Nm}$ flexo-extension moment predicted by the FE models and that measured by Panjabi et al (1994).

\subsection{Stress result comparison}

In subjects not afflicted with bone tissue related pathologies, disc injury within physiological load represents one of the main causes of the alteration of the spine behaviour and, therefore, pain. In particular, the interface between intervertebral discs and vertebral surfaces represents the most critical region for the onset of spinal diseases. Moreover, some recent studies (Costi et al., 2007; Wilson et al., 2003) showed how the shear effects are dominant in disc tissue failures. For these reasons, it was considered interesting to plot, for the more stressed disc, in Panjabi configuration (Panjabi et al 1994), the maps of the maximum shear stress for flexion and extension moments and to compare the distributions for the two models, with and without endplates, in order to underline how the presence of the endplates allow the reduction of the stress condition in the intervertebral disk.

The results for the flexion moment (Fig. 15) indicate that the greater values of the stresses were located at L5-S1 levels just in the interfaces between disc and vertebrae across the posterior and posterolateral zone for both models but the model without CEP reach stress level 1.5 times grater.

A similar result was obtained for the extension moment load case. In fact, the model without EP shows a grater average stress values in comparison with the model with EP (Fig 16).

Finally the stress responses of the two models, as expected, highlight that the most risky load condition corresponds to the flexion moment. In this case, in fact, the maximum stress values is $31 \mathrm{MPa}$ compared to a value of $4 \mathrm{MPa}$ calculated in the extension test. 

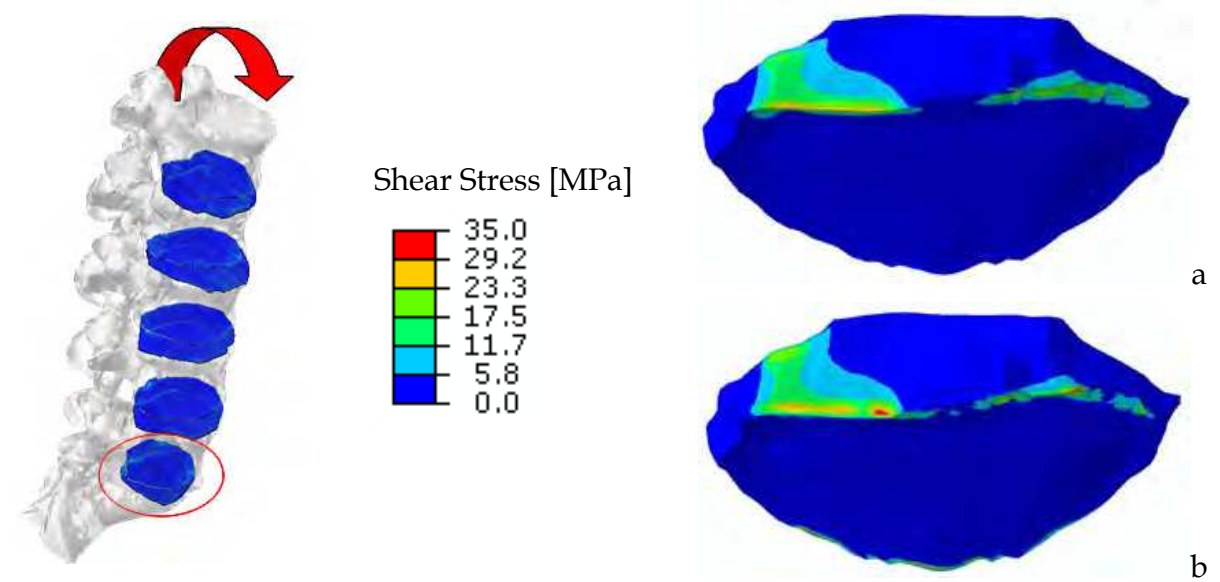

Fig. 15. Maximum shear stress distribution under a $10 \mathrm{Nm}$ flexion moment for disc L5-S1: with (a) and without endplates (b).
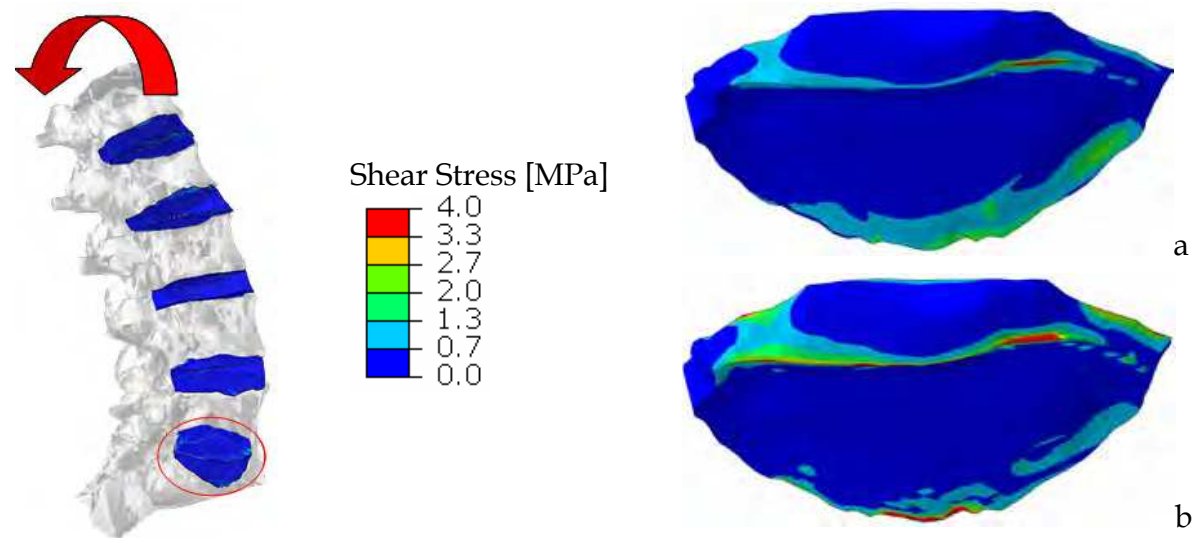

Fig. 16. Maximum shear stress distribution under a $10 \mathrm{Nm}$ extension moment for disc L5-S1: with (a) and without endplates (b).

\section{Conclusion}

With the aim of understanding the influence of the CEP in the modelling of the lumbar spine segment two numerical models of the lumbar rachis, differing exclusively in the presence of the cartilaginous endplates, were created and compared.

The complete model could be considered a valid numerical representation of the threedimensional load-displacement behaviour of the human lumbosacral spine at almost all vertebral levels. The FE model, infact, presents some interesting similarities with the informations about the spine known by literature. First of all the spinal behaviour in extension and in flexion is non linear and asymmetric in agreement with literature. The 
average highest $\mathrm{ROM}$ for each segment in flexion $\left(6.5^{\circ}\right)$ is usually much bigger than in extension $\left(-4.3^{\circ}\right)$. Furthermore while in extension the maximum rotation value has little variation between upper $\left(-5.4^{\circ}\right.$ for L5-S1 level) and lower $\left(-3.8^{\circ}\right.$ for L3-L4) segments, in flexion this range is much bigger from $4.9^{\circ}$, in L1-L2, to $8.3^{\circ}$, in L5-S1.

In particular the created models were used to study of the influence of the presence of the endplates on the mechanical response of the lumbar rachis under static loading.

Each intervertebral disc, in fact, is surrounded with two cartilagineous layers that constitute the interface between the discs and the vertebral bodies.

The analysis of the results allowed us to demonstrate the great importance of the endplates. Firstly the reduction of the stress and strain ranges to which the discs are subjected demonstrates the ability of the endplates to perform a sort of protection for the disc avoiding the direct contact between the soft tissue of the disc and the hard bone of the vertebrae.

At the same time their presence determined significant changes in the relative rotation between each couple of vertebrae, as stated in the first section of the analysis of the obtained results.

The model with endplates is able to follow more accurately the trend of experimental curves.

Moreover a perfect coincidence between numerical and experimental results is not possible due to all the variables involved in this kind of problems.

First of all we have to consider that the behaviour of human tissues, here univocally characterized, is affected by a series of factors including, for example, the age, the alimentation, the lifestyle of the subject; in addition the geometry of the rachis, that changes for all subjects, certainly influences its mechanical response under load. For this reason we can state that the behaviour of this numerical model qualitatively responds to the reported values present in literature.

Consequently the created model could be considered as a valuable tool for the study and mechanical analysis of the lumbar segment in the perspective of using it as a support for clinical analysis.

\section{References}

Adams, M.A. \& Roughley, P.J. (2006). What is intervertebral disc degeneration, and what causes it? Spine, Vol.31, No. 18, (August 2006), pp. 2151-2161, ISSN 1528-1159

Broberg, K. B. (1983). On the mechanical behaviour of the intervertebral disc. Spine, Vol.8, No.2, (March 1983), pp. 151-165, ISSN 1528-1159

Chazal, J. ; Tanguy, A. ; Bouges, M. ; Gaurel, G. ; Escande, G.; Guillot, M. \& Vanneuville, G. (1985). Biomechanical properties of spinal ligaments and an histological study of the supraspinal ligament in traction. Journal of Biomechanics, Vol.18, No.3, (March 1985),pp. 167-176, ISSN 0021-9290

Costi, J.J.; Stokes, I.A.; Gardner Morse, M.; Laible, J.P.; Scoffone, H.M. \& Iatridis, J.C. (2007). Direct measurement of intervertebral disc maximum shear strain in six degrees of freedom: Motion that place disc tissue at risk injury. Journal of Biomechanics, Vol.40, No.11, (October 2007), pp. 2457-2466, ISSN 0021-9290

Devor, M. \& Tal, M. (2009). What causes low back pain? Pain, Vol.142, No.1-2, (March 2009), pp. 11-12, ISSN 0304-3959 
Ebara, S., Iatridis, J.C., Setton, L.A., Foster, R.J., Mow, V.C., Weidenbaum, M., 1996. Tensile properties of nondegenerate human lumbar annulus fibrosus. Spine, Vol.21, No.4, (February 1996), pp. 452-461, ISSN 0362-2436

Eberlein, R.; Holzapfel, G.A. \& Schulze-Bauer, C.A.J. (2001). An anisotropic model for annulus tissue and enhanced finite element analysis of intact lumbar disc bodies. Computer Methods in Biomechanic and Biomedical Engeeniering, Vol.4, No.3, (March 2001), pp 209-229, ISSN 1476-8259

Eberlein, R.; Holzapfel, G. \& Fröhlich, M. (2004). Multi-segment FEA of the human lumbar spine including the heterogeneity of the annulus fibrosus. Computational Mechanics, Vol.34, No.2, (July 2004) pp.147-163, ISSN 1432-0924

Goel, V.K.; Monroe, T.; Gilbertson, L.G. \& Brinckmann, P. (1995). Interlaminar shear stresses and laminae separation in a disc. Spine, Vol.20, No.6, (March 1995), pp. 689-698, ISSN 0362-2436

Goto, K.; Tajima, N.; Chosa, E.; Totoribe, K.; Kuroki, H.; Arizumi, Y. \& Arai, T. (2002). Mechanical analysis of the lumbar vertebrae in the three-dimensional finite element method moments in which intradiscal pressure in the nucleus pulposus was used to establish the model. Journal of Orthopaedic Science, Vol.7, No.2, (March 2002), pp. 243-246, ISSN 1436-2023

Goto, K.; Tajima, N.; Chosa, E.; Totoribe, K.; Shinichiro, S. \& Kuroki, H. (2003). Effect of lumbar spinal fusion on the orther lumbar intervertebral levels (three dimensional finite element analyses). Journal of Orthopaedic Science, Vol.8, No.4, (July 2003), pp. 577-584, ISSN 1436-2023

Latorraca, A. \& Forni Niccolai Gamba, C. (2004). Analysis on 149 consecutive cases of intervertebral disc prolepses operated with microendoscopic (MetrX) technique. Reumatismo, Vol.56, No.1, (Marzo 2004), pp. 31-35, ISSN 0048-7449

Markolf, K.L. \& Morris, J.M. (1974). The structural components of the vertebral disc. A study of their contribution to the ability of the disc to withstand compressive force. The Journal of Bone and Joint Surgery Am., Vol.56, No.4, (June 1974), pp. 675-687, ISSN 0021-9355

Moramarco, V.; Pérez Del Palomar, A.; Pappalettere, C. \& Doblaré, M (2010). An accurate validation of a computational model of a human lumbosacral segment. Journal of Biomechanics, Vol.43, No.2, (Jenuary 2010), pp. 334-342, ISSN 0021-9290

Natarajan, R.N.; Williams, J.R. \& Andersson, G.B.J. (2004). Recent advances in analytical modelling of lumbar disc degeneration. Spine, Vol.29, No.23, (December 2004), pp. 2733-2741 ISSN 1528-1159

Noailly, J. (2009). Model developments for in silico studies of the lumbar spine biomechanics, PhD Thesis, Technical University of Catalonia, Barcelona, Spain

Panjabi, M.M.; Oxland, T.R.; Yamamoto, I. \& Crisco, J.J. (1994). Mechanical behaviour of the human lumbar and lumbosacral spine as shown by three dimensional loaddisplacement curves. The Journal of Bone and Joint Surgery Am., Vol.76, No.3, (March 1994), pp. 413-424, ISSN 0021-9355

Pérez del Palomar, A.; Calvo, B. \& Doblaré M. (2008). An accurate finite elements model of the cervical spine under quasi-static loading. Journal of Biomechanics, Vol.41, No.3, (January 2008), pp. 523-531, ISSN 0021-9290 
Pintar, F.A.; Yoganandam, N.; Myers, T.; Elhagediab, A. \& Sances Jr., A. (1992). Biomechanical properties of human lumbar spine ligaments. Journal of Biomechanics, Vol.25, No.11, (November 1992), pp. 1351-1356, ISSN 0021-9290

Rohlmann, A.; Bauer, L.; Zander, T.; Bergmann, G. \& Wilke, H.J. (2006). Determination of trunk muscle forces for flexion and extension by using a validated finite element model of the lumbar spine and measured in vivo data. Journal of Biomechanics, Vol.39, No.6, (January 2006), pp.981-9, ISSN 0021-9290

Wilson, W.; van Rietbergen, B.; van Donkelaar, C.C. \& Huiskes, R. (2003). Pathways of load induced cartilage damage causing cartilage degeneration in knee after meniscectomy. Journal of Biomechanics, Vol.36, No., (June 2003), pp. 845-851, ISSN 0021-9290

Zander, T.; Rohlmann, A. \& Bergmann, G. (2009). Influence of different artificial disc kinematics on spine biomechanics. Clinical biomechanics, Vol.24, No.2, (February 2009), pp. 135-142, ISSN 0268-0033 


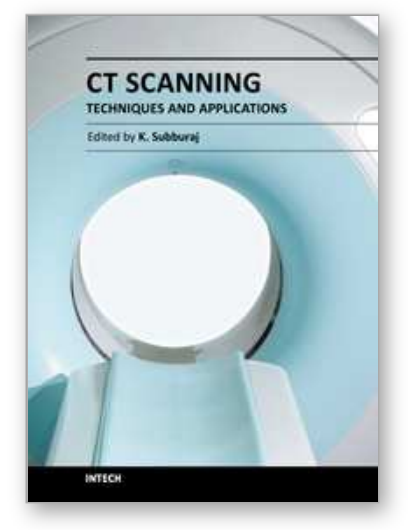

\author{
CT Scanning - Techniques and Applications \\ Edited by Dr. Karupppasamy Subburaj
}

ISBN 978-953-307-943-1

Hard cover, 348 pages

Publisher InTech

Published online 30, September, 2011

Published in print edition September, 2011

Since its introduction in 1972, X-ray computed tomography (CT) has evolved into an essential diagnostic imaging tool for a continually increasing variety of clinical applications. The goal of this book was not simply to summarize currently available CT imaging techniques but also to provide clinical perspectives, advances in hybrid technologies, new applications other than medicine and an outlook on future developments. Major experts in this growing field contributed to this book, which is geared to radiologists, orthopedic surgeons, engineers, and clinical and basic researchers. We believe that CT scanning is an effective and essential tools in treatment planning, basic understanding of physiology, and and tackling the ever-increasing challenge of diagnosis in our society.

\title{
How to reference
}

In order to correctly reference this scholarly work, feel free to copy and paste the following:

Vincenzo Moramarco, Claudia Macchia, Carmine Pappalettere and Amaya Pérez del Palomar (2011). Influence of End-Plates on Biomechanical Response of the Human Lumbosacral Segment, CT Scanning Techniques and Applications, Dr. Karupppasamy Subburaj (Ed.), ISBN: 978-953-307-943-1, InTech, Available from: http://www.intechopen.com/books/ct-scanning-techniques-and-applications/influence-of-end-plates-onbiomechanical-response-of-the-human-lumbosacral-segment

\section{INTECH}

open science | open minds

\author{
InTech Europe \\ University Campus STeP Ri \\ Slavka Krautzeka 83/A \\ 51000 Rijeka, Croatia \\ Phone: +385 (51) 770447 \\ Fax: +385 (51) 686166 \\ www.intechopen.com
}

\author{
InTech China \\ Unit 405, Office Block, Hotel Equatorial Shanghai \\ No.65, Yan An Road (West), Shanghai, 200040, China \\ 中国上海市延安西路65号上海国际贵都大饭店办公楼405单元 \\ Phone: +86-21-62489820 \\ Fax: +86-21-62489821
}


(C) 2011 The Author(s). Licensee IntechOpen. This chapter is distributed under the terms of the Creative Commons Attribution-NonCommercialShareAlike-3.0 License, which permits use, distribution and reproduction for non-commercial purposes, provided the original is properly cited and derivative works building on this content are distributed under the same license. 